\title{
A bibliometric study: Journal of management research and analysis
}

\author{
Rajanikant Patel
}

Librarian, Faculty of Dental Sciences, NPDCH, Sankalchand Patel University, Visnagar, Gujarat, India

*Corresponding Author: Rajanikant Patel

Email: patelrajni1577@gmail.com

\begin{abstract}
The periodical is the main source of information and the most important communication medium. They play a major role in communicating the latest research results and publishing articles containing the latest developments in all areas of knowledge. This study of bibliometric analysis of a Journal of Management Research and Analysis carried out from the year 2014-2018. In this present bibliometric study, a total number of 183 contributions published in 17 issues of 5 volumes during the year 2014-2018. The detail like year/volume wise and issue wise distribution of contributions, year wise authorship pattern, geographical/state wise distribution of contributions, most productive author, year wise number of pages per article, year/volume wise citations with form of referred documents. The recorded data has been found that the majority contribution published in the journal are collaborative research, the degree of C.C. is 0.5737.
\end{abstract}

Keywords: Bibliometric analysis of JMRA, Distribution of contribution, Authorship pattern, Citation analysis, JMRA.

\section{Introduction}

Alan Prichard (1969) used for the first time the word "bibliometric" as "the application of mathematics and statistical methods to books and other means of communication". Dr. S. R. Ranganathan (1948) the similar terms was defining the form of Librametry. According to Tsay (2011), "bibliometric techniques using references to other documents can be applied to establish statistical models of the scientific communication flow". Bibliometric is a quantitative evaluation of the publication models of all macro and micro communications as well as their authors by mathematical and statistical calculation. (Sengupta, 1985) Also there have been several bibliometric analyses of specific subject areas such as Zhao \& Logan (2002), Hols Apple \& Luo (2003) and Cai \& Card (2008).

Although bibliometric methods are most often used in the field of library and information science, bibliometric has many applications in other fields. In fact many research areas use bibliometric methods to explore the impact of their field, the quantitative analysis of publications, set of researchers/publications using bibliographic details including author, publication year, citation, figure and graph, pages length in the text etc. The bibliometric study is a simple statistical method of bibliographic counting to evaluate and quantify the growth of a subject. This helps to observe the growth of literature and research trends. The bibliometric study is primarily a citation analysis technique that involves the process of collecting, counting, analyzing and explaining citations given in various types of literature, thus contributing to the recognition of important sources of information. It is an emerging research unit in the field of library and information sciences.

\section{Literature Review}

Desai, K. D. (2014) bibliometric analysis of Desidoc journal of Library and Information Technology, Roy, S. \& Basak, M. (2013) a bibliometric study of Journal of Documentation, Kumar, Manoj \& Moorthy, A. L. (2011) bibliometric study of DJLIT from 2001 - 2010, Thanuskodi,
S. (2011) a bibliometric analysis of Indian journal of Chemistry (2005-2009), Natter, S. (2009) scientometric analysis of Indian journal of Physics (2004-2008), Singh, Mittal \& Ahmed (2006) a bibliometric study of literature on digital libraries, Paul, G. \& Deoghurai, S. (2014) Indian journal of Physics from the year 2004 - 2013 and Vellaichamy, A. \& Jayshankar, R. (2015) examined bibliometric analysis in the journal 'Webology' during the period 2004 -2013. Above past literature covers various parameters like distribution of contribution, authorship pattern, growth pattern, content coverage, degree of collaboration, geographical distribution, average number of reference per contribution, citation analysis, most prolific author and form of documents used by contributors.

\section{Need for the Study}

The expanding cost of periodicals and inadequate library budgets, the selection of exacting journal for a library very difficult. Therefore, library authorities are forced to reduce the number of journal subscriptions. Bibliometric analysis has many applications in the library and information science directory to identify trends in subject research, major journals and so on. These bibliometric studies will help librarians plan for better growth of collections.

\section{Scope/Limitation of the Study}

The "journal of research and management analysis", published by the innovative publication Pvt. Ltd., New Delhi. Double-blind peer review that provides specialized academic support and an important reference for encouraging and disseminating research and practice in management research. Journal of management research and analysis is a quarterly international referred journal published to provide an online publishing platform for academic, management/multidisciplinary researchers and students to publish their original work. The full text of the journal is available online at https://innovativepublication.com/journal/JMRA. The journal is listed as follows: Google Scholar, Academia.edu, 
Cite factor, Crossref, Infobaseindex, OAJI, Research Bible, SJIF and University Grants Commission (UGC). The study is limited to articles published in volumes 01 to 05 of the journal (JMRA) from 2014 to 2018 only. (https://innovativepublication.com/journal-about-us/JMRA).

\section{Objective}

1. To know year and volume wise distribution of contributions

2. To examine authorship pattern

3. To analyze geographical distribution of contributions

4. To find most productive author

5. To find the average length of articles

6. To study the form of referred documents or year wise distribution of citations

\section{Methodology}

For this study total number of 183 published articles in the 17 issues of 5 volumes. The recorded data (in Microsoft Excel) has been calculated and represented in tabular form and analyzed than interpreted.

\section{Data Analysis and Interpretation}

Table 1 is representative year and volume wise distribution of articles. There are 183 contributions published in 01 to 05 volumes during 2014 - 2018. 78 out of 183 articles published in volume fifth of the year 2018, followed by 37 articles in the year 2015, 29 articles in the year 2017 and lowest articles published in volume first of the year 2014 i.e. $11(6.01 \%)$. The highest article published in the month of January - March and lowest in the month of April - June.

Table 2 indicates author's contribution of published articles in different authorship patterns of the journal of management research and analysis. Total 183 published articles involve as a part of this study during $2014-2018$.
The comparison of published publications of single authorship pattern by author for this study is $(n=78)$. Out of total publication the highest publications published as a single authored in $2018(n=27)$, followed by year 2015 $(n=19)$ and the lowest publications by single authored pattern in $2014(\mathrm{n}=06)$.

The comparison of published publications of two authorship pattern by author for this study period is $(n=76)$. Out of total publication the highest publications published as a two authored in $2018(n=37)$, followed by year 2015 and $2017 \quad(n=14)$ and the lowest publications by two authored pattern in $2014(\mathrm{n}=01)$.

The comparison of published publications of three authorship pattern by author for this study is $(n=25)$. Out of total publication the highest publications published as a three authored in $2018(\mathrm{n}=12)$, followed by year 2014 and $2016(n=04)$ and the lowest publications by three authored pattern in $2017(n=02)$. The comparison of total published publications of Four and more than five authorship pattern by author for this study is $(\mathrm{n}=02)$.

Total single authored articles published by author is $(n=78)$ and joint author publications $(n=105)$. There are clearly shows that the majority authors are used publication patterns as a collaborative authored in the total publications of journal of management research and analysis. The collaboration coefficient (CC) measure collaborative research pattern by K. Subramanian, (1983) has been applied; the degree of authorship collaboration of the journal (JMAR) is 0.5737 .

$$
\mathrm{C} \frac{\mathrm{NM}}{\mathrm{NM}+\mathrm{NS}}
$$

$\mathbf{C}=(105 / 105+78)=\mathbf{0 . 5 7 3 7}$

Table 1: Year and volume wise distribution of articles.

\begin{tabular}{|c|c|c|c|c|c|c|}
\hline \multirow[b]{2}{*}{ Month } & \multicolumn{5}{|c|}{ Year and Volume Number } & \multirow[b]{2}{*}{ Total Articles } \\
\hline & $\begin{array}{c}2014 \\
(01)\end{array}$ & $\begin{array}{c}2015 \\
(02)\end{array}$ & $\begin{array}{c}2016 \\
(03)\end{array}$ & $\begin{array}{l}2017 \\
(04)\end{array}$ & $\begin{array}{c}2018 \\
(05)\end{array}$ & \\
\hline January- March & 11 & 10 & 09 & 05 & 15 & 50 \\
\hline April - June & 00 & 10 & 05 & 06 & 21 & 42 \\
\hline July- September & 00 & 10 & 07 & 08 & 22 & 47 \\
\hline October-December & 00 & 07 & 07 & 10 & 20 & 44 \\
\hline Total Contribution & 11 & 37 & 28 & 29 & 78 & 183 \\
\hline$\%$ & 6.01 & 20.22 & 15.30 & 15.85 & 42.62 & 100 \\
\hline
\end{tabular}

Table 2: Contribution of authors and authorship pattern

\begin{tabular}{|c|c|c|c|c|c|c|c|}
\hline \multirow[t]{3}{*}{ Year } & \multicolumn{5}{|c|}{ Authorship pattern } & \multirow{3}{*}{$\begin{array}{c}\text { Sub-total } \\
\text { (collaborative) }\end{array}$} & \multirow{3}{*}{$\begin{array}{c}\text { Total } \\
=(1+\text { Subtotal })\end{array}$} \\
\hline & \multirow[t]{2}{*}{ Single } & \multicolumn{4}{|c|}{ Collaborative } & & \\
\hline & & Two & Three & Four & Five \& More & & \\
\hline 2014 & 06 & 01 & 04 & 00 & 00 & 05 & 11 \\
\hline 2015 & 19 & 14 & 03 & 00 & 01 & 18 & 37 \\
\hline 2016 & 14 & 10 & 04 & 00 & 00 & 14 & 28 \\
\hline 2017 & 12 & 14 & 02 & 00 & 01 & 17 & 29 \\
\hline 2018 & 27 & 37 & 12 & 02 & 00 & 51 & 78 \\
\hline Total & 78 & 76 & 25 & 02 & 02 & 105 & 183 \\
\hline$\%$ & 42.63 & 41.53 & 13.66 & 1.09 & 1.09 & 57.38 & 100 \\
\hline
\end{tabular}


Table 3: Geographical distributions of articles

\begin{tabular}{|c|c|c|c|c|c|c|c|c|}
\hline \multirow{2}{*}{ S. No. } & \multirow{2}{*}{ State } & \multicolumn{5}{|c|}{ Year wise contribution } & \multirow{2}{*}{ Total } & \multirow{2}{*}{$\%$} \\
\hline & & 2014 & 2015 & 2016 & 2017 & 2018 & & \\
\hline 1 & Tamil Nadu & 03 & 07 & 07 & 05 & 15 & 37 & 20.22 \\
\hline 2 & Maharashtra & 02 & 08 & 05 & & 03 & 18 & 9.84 \\
\hline 3 & New Delhi & 02 & 02 & & 03 & 11 & 18 & 9.84 \\
\hline 4 & Madhya Pradesh & 01 & 06 & 05 & 01 & 04 & 17 & 9.29 \\
\hline 5 & Uttar Pradesh & 02 & 03 & 01 & 04 & 07 & 17 & 9.29 \\
\hline 6 & Karnataka & & & 02 & 03 & 08 & 13 & 7.10 \\
\hline 7 & Gujarat & & 03 & 02 & 04 & 02 & 11 & 6.01 \\
\hline 8 & Foreign & 01 & 04 & 02 & 02 & 01 & 10 & 5.46 \\
\hline 9 & Odisha & & & 02 & 03 & 04 & 09 & 4.92 \\
\hline 10 & Harayana & & 03 & & & 04 & 07 & 3.82 \\
\hline 11 & Punjab & & & & 01 & 05 & 06 & 3.28 \\
\hline 12 & West Bengal & & & 01 & & 03 & 04 & 2.18 \\
\hline 13 & Kerala & & 01 & & & 01 & 02 & 1.09 \\
\hline 14 & Rajasthan & & & & & 02 & 02 & 1.09 \\
\hline 15 & Pondicherry & & & & 01 & 01 & 02 & 1.09 \\
\hline 16 & Telangana & & & & 01 & 01 & 02 & 1.09 \\
\hline 17 & Jammu and Kashmir & & & & & 02 & 02 & 1.09 \\
\hline 18 & Arunchal Pradesh & & & & & 01 & 01 & 0.55 \\
\hline 19 & Himachal Pradesh & & & & & 01 & 01 & 0.55 \\
\hline 20 & Bihar & & & & & 01 & 01 & 0.55 \\
\hline 21 & Chhattisgarh & & & 01 & & & 01 & 0.55 \\
\hline 22 & Uttarkhand & & & & & 01 & 01 & 0.55 \\
\hline 23 & Jharkhand & & & & 01 & & 01 & 0.55 \\
\hline & Total & 11 & 37 & 28 & 29 & 78 & 183 & 100 \\
\hline
\end{tabular}

Above table depict the geographical distribution of contributions of the journal under the study. Out of 183 contributions, the highest number $(n=37)$ 20.22\%, followed by Maharashtra and New Delhi $(n=18)$ and Madhya Pradesh, Uttar Pradesh, Karnataka, Gujarat and Foreign are fourth, fifth, sixth, seventh and eighth place having $(n=17),(n=13),(n=11)$ and $(n=10)$ contributions respectively. Out of 183 contributions (National and International) $(n=173)$ contributions have been made by Indian states.

Table 4: Productive authors

\begin{tabular}{|c|c|c|c|}
\hline S. No. & Rank & Author & No. of paper \\
\hline 1 & 1 & R. Ganapathi & 17 \\
\hline 2 & 2 & Jayant Sonwalkar & 09 \\
\hline 3 & 3 & Ashok Kumar Panigrahi & 06 \\
\hline 4 & 3 & Chandan Maheshkar & 06 \\
\hline 5 & 4 & Krunal Bhuva & 03 \\
\hline 6 & 4 & Sachin Mittal & 03 \\
\hline 7 & 4 & Sandeep Hegde & 03 \\
\hline 8 & 4 & Sweta Singh & 03 \\
\hline 9 & 4 & Thankachan Jose Kaitharath & 03 \\
\hline 10 & 5 & Anjala Kalsie & 02 \\
\hline 11 & 5 & Archana Singh & 02 \\
\hline 12 & 5 & Ashwini & 02 \\
\hline 13 & 5 & Atul Kumar & 02 \\
\hline 14 & 5 & B. S. Bhatia & 02 \\
\hline 15 & 5 & Bhumika Achhnani & 02 \\
\hline 16 & 5 & Chandni Mehta & 02 \\
\hline 17 & 5 & Daman Jeet & 02 \\
\hline 18 & 5 & Garima Singh & 02 \\
\hline 19 & 5 & H. Parshuram & 02 \\
\hline 20 & 5 & K. N. Jayakumar & 02 \\
\hline
\end{tabular}




\begin{tabular}{|l|l|c|c|}
\hline 21 & 5 & Kavita Khanna & 02 \\
\hline 22 & 5 & Paresh Bali & 02 \\
\hline 23 & 5 & Pooja Sehgal Tabeck & 02 \\
\hline 24 & 5 & R. K. Gupta & 02 \\
\hline 25 & 5 & R. K. Sharma & 02 \\
\hline 26 & 5 & Raghavendra P. Kumar & 02 \\
\hline 27 & 5 & Rama Krishna Mishra & 02 \\
\hline 28 & 5 & Ranjita Behera & 02 \\
\hline 29 & 5 & Rekha Sharma & 02 \\
\hline 30 & 5 & Sandeep Malik & 02 \\
\hline 31 & 5 & Sarwade Chetan W. K. & 02 \\
\hline 32 & 5 & Shahid Ali & 02 \\
\hline 33 & 5 & Suman Kalyan Choudhury & 02 \\
\hline 34 & 5 & Vijaya Kumar S. & 02 \\
\hline
\end{tabular}

The most productive authors with their number of publications are given in the table. The most productive and ranking authors found in the study in order of the number of contributions is R. Ganapathi, first rank of the list with 17 publications, followed by Jayant Sonwalkar with 09 publications, Ashok Kumar Panigrahi and Chandan Maheshkar with 06 publications, five authors are published 03 publications and twenty five authors are secure fifth rank with 02 publications.

Table 5: Lengths of articles

\begin{tabular}{|c|c|c|c|c|c|c|c|}
\hline \multirow{2}{*}{ Length (pages) } & \multicolumn{5}{|c|}{ Year } & \multirow{2}{*}{ Total } & \multirow{2}{*}{$\%$} \\
\hline & 2014 & 2015 & 2016 & 2017 & 2018 & & \\
\hline Three & 00 & 01 & 05 & 03 & 03 & 12 & 6.56 \\
\hline Four & 00 & 05 & 04 & 02 & 13 & 24 & 13.12 \\
\hline Five & 00 & 05 & 07 & 09 & 18 & 39 & 21.31 \\
\hline Six & 01 & 05 & 02 & 05 & 13 & 26 & 14.21 \\
\hline Seven & 00 & 04 & 03 & 04 & 08 & 19 & 10.38 \\
\hline Eight & 02 & 05 & 01 & 01 & 16 & 25 & 13.66 \\
\hline Nine & 01 & 03 & 03 & 01 & 02 & 10 & 5.46 \\
\hline Ten \& More & 07 & 09 & 03 & 04 & 05 & 28 & 15.30 \\
\hline Total & 11 & 37 & 28 & 29 & 78 & 183 & 100 \\
\hline
\end{tabular}

Above table 5 represent length of articles of the journal for year $2014-2018$, total 183 articles published. Out of $(n=39)$ published article by author have the length of five pages, followed by $(n=28)$ articles with ten and more pages, $(n=26)$ articles with six pages, $(n=25)$ articles with eight pages, $(n=24)$ articles with four pages, and the remaining articles have below the length of fifteen pages.

Table 6: Forms of referred documents and distribution of citation per volume

\begin{tabular}{|c|c|c|c|c|c|c|c|}
\hline \multirow[b]{2}{*}{ Forms of Document } & \multicolumn{5}{|c|}{ Year \& Volume wise citation } & \multirow[b]{2}{*}{$\begin{array}{l}\text { Total No. of } \\
\text { Citation }\end{array}$} & \multirow[b]{2}{*}{$\%$} \\
\hline & $\begin{array}{c}2014 \\
(01)\end{array}$ & $\begin{array}{c}2015 \\
(02)\end{array}$ & $\begin{array}{c}2016 \\
(03)\end{array}$ & $\begin{array}{r}2017 \\
(04)\end{array}$ & $\begin{array}{c}2018 \\
(05)\end{array}$ & & \\
\hline Journals & 68 & 298 & 373 & 192 & 803 & 1734 & 52.61 \\
\hline Books & 12 & 82 & 75 & 51 & 155 & 375 & 11.38 \\
\hline Thesis/Dissertation & 04 & 03 & 04 & 02 & 11 & 24 & 0.73 \\
\hline $\begin{array}{l}\text { Conference/Workshop/Seminar/Symposi } \\
\text { a/Proceeding }\end{array}$ & 17 & 72 & 50 & 55 & 130 & 324 & 9.83 \\
\hline Manuals/Handbooks/Guides/Guidelines & 04 & 17 & 32 & 23 & 67 & 143 & 4.34 \\
\hline Report/Projects & 02 & 31 & 34 & 23 & 70 & 160 & 4.85 \\
\hline Software & 00 & 00 & 00 & 00 & 00 & 00 & 00 \\
\hline Standard/Patents & 00 & 00 & 02 & 02 & 01 & 05 & 0.15 \\
\hline Websites & 35 & 95 & 57 & 60 & 284 & 531 & 16.11 \\
\hline Distribution of citation per volumes & 142 & 598 & 627 & 408 & 1521 & 3206 & 100 \\
\hline$\%$ & 4.31 & 18.14 & 19.02 & 12.38 & 46.15 & 3296 & 100 \\
\hline
\end{tabular}


Above table define forms of referred documents and distribution of citation per volume. Among total 3296 citations, highest in the year $2018(\mathrm{n}=1521)$, followed by year $2016(n=627)$ and the lowest in the year $2014(n=142)$ authors used various forms of referred documents. The contributors preferred journal as a sources of information and the top position with the highest number of citations $(n=1734)$, the second highest position by websites with $(n=531)$ citations, the form of document as a books with $(n=375)$ and used by author the preparation of contribution other form of documents listed as per table.

This five year studies of JMRA, total 3296 citations used. It's growing nearly by 142 references in year 2014 to 1521 references in year 2018. The references referred the age of year 2011 to 2015 is $(n=831)$, followed by references age of the year 2006 to $2010(n=695)$, references age of the year 2001 to $2005(n=552)$, small number of references used by author up to 1950 . Also define most frequently cited journal used by contributors, the top cited journals are Journal of marketing, The Indian journal of industrial relations, African journal of business management and Journal of academy of marketing science.

\section{Findings and Conclusion}

On the basis of above study the following major findings are describe,

1. Highest 78 articles was published in volume no. - 05 and lowest 11 articles published in volume no. -01 .

2. Majority of article are contributed by single authored $(n=78)$ compare with two, three, four and more authorship.

3. Among the Indian states, the national contribution is maximum.

4. Among the contribution of geographical distribution, Tamil Nadu has top the list of contributor.

5. R. Ganapathi is most productive author with seventeen (17) contributions.

6. The average number of references per articles i.e. 18 .

It is concluded in the present study from the year 20142018, there are 183 articles published from volume 01 to 05 of JMRA. The highest number of articles published in the year 2018. Multiple authors have shown keen interest in making contributions from during the study year. Out of twenty three places, the contributions of 173 articles (94.54\%) come from Indian states. The studies reveal that the majority of contributor preferred journal as a source of information for writing papers. The average length of pages of the contributions is five pages with $21.31 \%$.

\section{References}

1. https://innovativepublication.com/journal/JMRA (Access on 15th April to $10^{\text {th }}$ May 2019)

2. Shah Sapan M. (2016) A Bibliometric Analysis of International Journal of Agriculture Sciences (2009-2014). Asian J Multidiscip Stud, 2016;4(2):151-7.

3. Vellaichamy, A. \& Jayshankar, R. Bibliometric analysis of the Journal of Webology from 2004 - 2013. J Adv Libr Inf Sci 2015;4(1):7-13.

4. Sharma, C. A. S. Authorship trends and collaborative research in veterinary sciences: a bibliometric study. Chinese Librarianship: An Int Electronic J 2012;34.

5. Kumar, Manoj \& Moorthy, A. L. Bibliometric analysis of DESIDOC Journal of Library and Information Technology during 2001-2010. DESIDOC J Libr Inf Technol 2011;31(3):203-8.

6. Thanuskodi S. Bibliometric analysis of the Indian Journal of Chemistry, Library Philosophy and Practice. 2011.

7. Tsay M.Y. A bibliometric analysis on the Journal of Information Science, Journal of Library and Information Science Research, 2011;5(2)(5).

8. Patra S K and Chand P, HIV/ AIDS research in India: A bibliometric study, Library and information research, 29 (2007), 124-134.

9. Raghavan, K. R. V. I. A bibliometric study. Annals of Library and Information Studies, J Food Sci Technol 2007;54(4):20712.

10. Annor, G. K. G. Authorship trends in Ghana Journal of Agricultural Science: a bibliometric study. Ghana Libr J 2007;19(1):41-64.

11. W. Glanzel (2003), Bibliometrics as a research field; a course on theory and application of bibliometric indicators. Access on $5^{\text {th }}$ may $2019,12.40 \mathrm{pm}$.

https://www.researchgate.net/.../242406991_Bibliometrics

12. Dhiman, A. K. Ethynobotany Journal: A ten years bibliometric study. IASLIC Bulletin, 2000;45(4):177-82.

13. Subramanyam K. (1983). Bibliometric Studies of Research Collaboration, A Review. J Inf Sci 1983;6(1):33-8.

14. Pritchard, A. (1969). Statistical bibliography or bibliometrics. $J$ Documentation, 1969;25(4):348-9.

15. https://en.wikipedia.org/wiki/Bibliometrics access on 25 th April 2019, 3.00 pm.

How to cite this article: Patel R. A bibliometric study: Journal of management research and analysis. J Manag Res Anal 2019;6(2):93-7. 